\title{
POR QUE A MAIORIA DOS PAIS E ALUNOS DEFENDE A REPROVAÇÃO?
}

\author{
MÁRCIA APARECIDA JACOMINI \\ Professora adjunta do Curso de Licenciatura Plena em Ciências da Universidade Federal \\ de São Paulo - Campus Diadema \\ marciajacomini@uol.com.br
}

\begin{abstract}
RESUMO
O objetivo do artigo é analisar a opinião de pais e alunos sobre a progressão continuada e a reprovação escolar. A pesquisa de campo, realizada em duas escolas municipais de São Paulo, teve duração de um ano letivo. Os dados foram coletados por meio de observação do cotidiano escolar e de entrevistas semiestruturadas com 56 pais e alunos, e organizados em categorias temáticas, de acordo com Bardin (2004). Duas questões centrais pautaram a pesquisa: Por que a maioria dos pais e dos alunos é contra a progressão continuada? Como construíram essa forma de pensar? A crença de que a reprovação exerce uma pressão "salutar" sobre os alunos que, por temor de perder o ano, estudariam mais e se sentiriam obrigados a ter bom comportamento e dedicação aos estudos, foi preponderante entre os sujeitos. Como as experiências escolares dos sujeitos não confirmam tais efeitos da reprovação anual, questionou-se por que eles continuam pensando assim? Os depoimentos sugerem, entre outros aspectos, que os entrevistados se apropriaram do discurso dominante, contrário às políticas de não reprovação anual, sem refletir criticamente sobre suas próprias experiências de escolarização. ALUNOS - DEMOCRATIZAÇÃO DO ENSINO - PAIS - REPETÊNCIA
\end{abstract}

\begin{abstract}
WHY DO MOST PARENTS AND STUDENTS DEFEND SCHOOL RETENTION? This paper analyses the opinions of parents and students on social promotion by learning cycles. The field research was conducted in two public school in São Paulo City for a whole school year. Date were collected through observation of everyday school life and from semi-structured interviews with 56 parents and students, and organized into thematic categories, according to Bardin (2004). There were two central questions behind the research: Why are most parents and students against social promotion? How did they reach this way of thinking? The belief that retention exerts a "healthy" pressure on the students is a general assumption among them. So, for the subjects interviewed, pupils would felt obliged to study more, to behave well and to dedicate themselves to their studies. As the subject's school experiences do not confirm the
\end{abstract}

Este artigo foi produzido com os dados obtidos na pesquisa de campo que resultou em tese de doutorado (Jacomini, 2008). Uma parte da pesquisa foi financiada pelo Conselho Nacional de Desenvolvimento Científico e Tecnológico - CNPq. 
positive effects of school repetition, they were asked why they continue thinking in this way. Their statements suggest that they have appropriated the dominant discourse, which is against the social promotion policies, without thinking critically about their own school experiences. STUDENTS - DEMOCRATIZATION OF EDUCATION - PARENTS - GRADE REPETITION

Não estudamos para a vida, mas para a escola.

(Séneca)

Embora discussões sobre políticas de não reprovação anual tenham ocorrido no Brasil desde a década de 1920', foi somente a partir da década de I 960 que algumas redes públicas de ensino municipal e estadual organizaram o ensino de forma não seriada e adotaram políticas de não reprovação anual.

A primeira Lei de Diretrizes e Bases da Educação Nacional - LDB -, n. 4.024/6I, estabeleceu no art. 104 a possibilidade de organização do ensino não seriado em caráter experimental. Na Lei n. 5.692/7।, art. I4, a não seriação foi apresentada como alternativa de organização do ensino. A nova LDB, Lei n. 9.394/96, propõe, no art. 23, os ciclos entre outras possibilidades de organização do ensino. Os ciclos também estão presentes nos Parâmetros Curriculares Nacionais do Ensino Fundamental - PCN (Brasil, 1997).

Do ponto de vista legal, os ciclos na cidade de São Paulo foram formulados com base na proposta alternativa de organização do ensino expressa na Lei n. 5.692/7/2. Mesmo antes da atual LDB, várias redes públicas adotaram os ciclos e a progressão continuada como forma de organização de ensino, tendo isso contribuído para sua incorporação na Lei n. 9.394/96 e nos PCN. Após a aprovação da última LDB, outras redes públicas organizaram o ensino em ciclos e adotaram a progressão continuada. Em 2005, 19,6\% das matrículas do ensino fundamental no Brasil foram realizadas em redes de ensino ou escolas organizadas em ciclos; no estado de São Paulo, esse percentual correspondia a 76\%, e no município de São Paulo, a 80,3\% (Brasil, 2005).

I. Sobre essa questão, ver Almeida Júnior (1959).

2. O ensino na rede municipal de ensino de São Paulo foi organizado em ciclos em 1992, na gestão da prefeita Luiza Erundina de Souza, filiada então ao Partido dos Trabalhadores - PT. Nesse período, o ensino fundamental de oito anos passou a ter três ciclos: ciclo I, Iํ, 2으

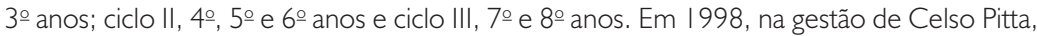
o ensino foi reorganizado em dois ciclos: ciclo I, correspondendo aos quatro primeiros anos do ensino fundamental, e ciclo II, aos quatro últimos anos. 
Dessa forma, pode-se dizer que as propostas de organização do ensino em ciclos e de progressão continuada ganharam expressão no cenário nacional a partir dos anos de 1980, com o ciclo básico de alfabetização - CBA ${ }^{3}$ - e, nos anos 1990, com a implantação, em algumas redes municipais e estaduais de ensino, dos ciclos e da progressão continuada em todo o ensino fundamental.

A organização do ensino em ciclos buscou incorporar às práticas pedagógicas e ao funcionamento da escola conhecimentos sobre o desenvolvimento e a aprendizagem das crianças e dos adolescentes produzidos no decorrer do século XX. Tais conhecimentos permitiram a compreensão sobre as diferenças individuais e as especificidades de cada criança na aquisição dos conhecimentos escolares, como parte da cultura geral, e conduziu à reflexão sobre a organização seriada do ensino e as práticas de reprovação anual.

Essa reflexão também foi impulsionada pela necessidade de se encontrarem meios para garantir a escolarização de milhares de crianças e adolescentes que passaram a ter acesso à escola de ensino fundamental com a obrigatoriedade do ensino dos 7 aos 14 anos, estabelecida pela Constituição Federal de 1967, e pela obrigatoriedade do ensino de I grau de 8 anos de acordo com a Lei n. 5.692/7I.

No entanto, embora as propostas de ciclos e progressão continuada tenham significado, em muitos casos, uma tentativa de reorganização da escola tendo em vista a democratização do ensino e da aprendizagem, ainda persistem as práticas de exclusão escolar. Nas redes de ensino seriadas, a exclusão, resultado do baixo desempenho escolar, ocorre principalmente pela reprovação e a evasão muitas vezes por ela provocada. Nas redes de ensino ou escolas com progressão continuada, apesar de os alunos não serem excluídos da escola devido ao baixo desempenho escolar, de modo geral eles não têm encontrado os meios para se apropriar do conhecimento e realizar seu processo de escolarização. Assim, embora não haja reprovação anual, uma parte da população continua sendo excluída, pelo menos parcialmente, do direito à educação. Esse processo tem ocorrido principalmente nas redes de

3. O CBA consistia num ciclo formado pelas antigas I’ e 2 $2^{\circledR}$ séries, sem reprovação na passagem de uma série para outra, cujo objetivo era ampliar o tempo para a alfabetização das crianças. Foi implantado na década de 1980 nos Estados de São Paulo, Paraná e Minas Gerais. 
ensino que implantaram a progressão continuada e não garantiram os recursos necessários a sua realização.

Apesar disso, é importante destacar o fato de a progressão continuada estar gerando discussões e pressão pela melhoria da qualidade do ensino, tanto em relação à organização da escola quanto às políticas educacionais.

Desde a implantação dos ciclos e da progressão continuada em algumas redes de ensino, várias pesquisas têm apontado como a resistência dos educadores à progressão continuada constitui um elemento que, combinado às precárias condições de funcionamento da escola, dificulta a construção de um novo eixo ordenador à prática pedagógica - o ensino e a aprendizagem, em contraposição à reprovação e à exclusão (Ambrosetti, 1990; Paro, 200 I ; Jacomini, 2002; Araújo, 2006). No entanto, ainda é pequeno o número de estudos dedicados a conhecer e analisar a opinião dos alunos e dos pais sobre essa temática.

Assim, entende-se ser necessário tentar avançar na compreensão dessas opiniões diante da tendência de oposição e crítica à implantação dos ciclos e da progressão continuada, apresentada pelos estudos com foco na análise da opinião e do posicionamento dos educadores em relação às políticas de não reprovação anual ${ }^{4}$, e do fato de as pesquisas que trabalharam com pais e alunos se dedicarem principalmente a apresentar a opinião desses em relação à progressão continuada.

Admitindo que a oposição à progressão continuada constitui a opinião hegemônica entre pais e alunos e que os estudos anteriores não se dedicaram a analisar os seus motivos, o propósito da pesquisa foi investigar por que a maioria dos pais e alunos pensa assim e como eles construíram essa forma de pensar, com vistas a elaborar algumas explicações que permitam aprofundar a compreensão sobre a oposição que esses atores têm apresentado às políticas de não reprovação anual.

Os dados e análises apresentados neste artigo fazem parte de pesquisa qualitativa realizada durante todo o ano letivo de 2005 em duas escolas municipais de São Paulo ${ }^{5}$. Foram realizadas atividades de observação e entrevistas

4. Consultar: Paro (200 I); Jacomini (2002); Viégas (2002); Steinvascher (2003); Araújo, (2006).

5. Para a escolha dos estabelecimentos escolares estabeleceu-se o seguinte critério: uma escola sem participação da comunidade nas discussões e decisões sobre o projeto político-pedagógico e outra cuja comunidade tivesse participado na elaboração do projeto político-pedagógico. 
com I 4 pais e 14 alunos de cada escola, perfazendo um total de 56 sujeitos $^{6}$. As informações provenientes das entrevistas foram organizadas por meio de categorias, de acordo com o conteúdo expresso nos depoimentos (Bardin, 2004). Neste texto, serão apresentados apenas os dados relativos às manifestações dos entrevistados acerca da defesa da reprovação escolar.

\section{COMO OS PAIS E OS ALUNOS EXPLICAM SUA OPOSIÇÃO À PROGRESSÃO CONTINUADA?}

\section{A reprovação como medida para garantir melhor aprendizagem}

A principal justificativa de pais e alunos para defender seu posicionamento contrário à progressão continuada é o fato de muitos alunos serem promovidos sem ter aprendido de forma adequada os conteúdos escolares. Eles argumentam que é necessário haver reprovação porque os alunos não podem ser promovidos se não alcançaram os objetivos estabelecidos para cada ano letivo. No imaginário de muitos pais e alunos, a reprovação aparece diretamente vinculada a uma segunda e "garantida" oportunidade de aprender. Acreditam também que a reprovação é uma medida importante para pressionar os alunos a estudar, contribuindo para a aprendizagem.

A maioria dos alunos vê a reprovação como algo necessário à escolarização e, em certo sentido, bom, porque "ajuda os alunos que não sabem". "É bom porque se a gente repetir tem mais uma chance pra aprender"; "Pra poder ajudar os alunos que não sabem, que não aprenderam”. Na percepção desses alunos, a reprovação é um meio para garantir a aprendizagem, por isso não deve deixar de existir.

Esse critério foi utilizado para saber se havia diferenças na opinião dos entrevistados devidas à participação da comunidade na escola.

6. Foram entrevistados alunos do terceiro ao oitavo ano do ensino fundamental e seus pais. Os critérios para a escolha dos alunos foram: representação de ambos os sexos, alunos que já haviam sido reprovados, alunos que nunca haviam sido reprovados, alunos com bom e com baixo desempenho escolar. Os próprios alunos indicaram os colegas com bom e baixo desempenho escolar para participar da pesquisa. $O$ desempenho escolar dos alunos foi posteriormente confirmado pelos pais e pelos professores. 
De acordo com os depoimentos de alguns alunos, a reprovação faz o aluno perceber que não havia tido uma boa aprendizagem e, ao repetir a "série", ele aprende o que não havia aprendido. A escola reprova "para o aluno se tocar que não fez o suficiente para passar de ano e voltar no próximo ano e aprender o que não tinha aprendido". Na opinião deles a reprovação funciona como medida corretiva. Ao ser reprovado, o aluno perceberá seu erro e voltará no ano seguinte mais disposto a estudar.

A opinião de muitos pais sobre a reprovação escolar reafirma a ideia de que ela contribui para o aluno aprender mais porque irá rever todo o conteúdo no ano seguinte.

Olha, no meu ponto de vista a reprovação é ótima, porque não adianta você passar de ano se você não entendeu nada e lá na frente você vai ficar perdido no tempo. É como se eu fosse participar de uma coisa que eu não tenho conhecimento... Eu acho que a reprovação ajuda, porque o que você não aprendeu nesse ano você volta tudo de novo e vai aprender pelo menos metade. (depoimento de mãe)

Essa mãe defendeu a reprovação como sendo uma coisa boa, apesar de a filha ter sido reprovada várias vezes e continuar com baixo desempenho escolar?.

Outros depoimentos atribuíram a existência da reprovação escolar ao fato de a escola precisar, para realizar o processo educativo, agrupar os alunos de acordo com o desempenho que eles apresentam em cada ano letivo. "A escola tem uma média e em cima disso ele [o aluno] tem que aprender a base de cada ano para chegar na $8^{a}$ série e ter opção de fazer o colegial”. A ideia da heterogeneidade e da diversificação dos conteúdos e das metodologias características de um ensino em ciclos parece não estar presente na concepção que os pais têm da organização do processo educativo.

7. Em uma das vezes em que a aluna foi reprovada, a mãe concordou que a menina não fosse à escola durante um período para que sua reprovação pudesse ser justificada por falta. Isso aconteceu no $3^{\circ}$ ano do ciclo I. Posteriormente, ela foi reprovada mais duas vezes no 4 응 ano do ciclo I. 
Diante da afirmativa de que os alunos aprendem mais quando repetem a "série", os pais cujos filhos haviam sido reprovados foram questionados sobre se isso tinha acontecido com seus respectivos filhos. Alguns afirmaram que sim, mas o filho continuava com desempenho abaixo da média da classe. Os pais parecem perceber que, mesmo repetindo o ano letivo, os filhos não aprendem o que poderiam e deveriam aprender.

Apesar de reconhecer que, se a filha tivesse sido reprovada no primeiro ano do ciclo I, não necessariamente teria sido alfabetizada, uma mãe disse achar que a reprovação teria sido boa para a filha porque ela teria aprendido pelo menos um pouco mais e não teria ficado tão perdida em relação às atividades do $2 \circ$ e $3 \circ$ anos do ciclo 1 .

Eu acho que ela poderia até não ter sido alfabetizada, mas eu acho que ela não

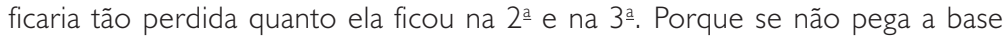
no começo, no meio fica difícil. Então eu acho que se ela tivesse repetido a $2^{a}$ série, aí pelo menos ela já ia conhecer as letras do alfabeto, ela nem conhecia, quando ela passou pra 2 a série ela nem sabia formar a palavra bola, a palavra Ana, não sabia completar uma frase, nada. Então ela foi pra $2^{\underline{a}}$ e ficou perdida no tempo do mesmo jeito.

É interessante observar como a fala dessa mãe denuncia a organização seriada dos conteúdos e das práticas escolares. Ao ter sido promovida para a "2 a série" ainda não alfabetizada, a aluna se deparou com um conteúdo e uma organização do trabalho pedagógico inadequados às suas necessidades, ou seja, foi posta diante de atividades que exigiam que ela soubesse ler e escrever, pelo menos um pouco, para realizá-las. Ao não ser capaz de responder às exigências daquela "série" e ao não ser atendida em suas necessidades, foi ficando cada vez mais defasada em relação ao grupo-classe. Isso explica, em parte, a conclusão da mãe ao dizer que teria sido melhor se ela tivesse sido reprovada. Ela acredita que, se a filha tivesse ficado junto com os alunos que estavam iniciando o processo de alfabetização, teria tido mais oportunidade de aprender a ler e escrever.

Pelos depoimentos dos entrevistados, percebe-se que está fortemente presente na concepção dos pais e dos alunos, construída historicamente, que a reprovação é inerente ao processo de ensino-aprendizagem e tem a finalidade 
de selecionar anualmente os alunos que alcançaram os objetivos previamente estabelecidos para o prosseguimento dos estudos nas séries mais adiantadas, separando-os daqueles que não aprenderam a contento os conteúdos daquela série.

Por acreditarem que a reprovação é uma forma eficiente de garantir uma aprendizagem melhor, alguns pais e alunos - mesmo percebendo que muitas vezes o aluno continua com baixo desempenho escolar após ter sido reprovado - referem-se à reprovação como "redentora". Em certo sentido, eles depositam nela a expectativa de realização de um ensino de qualidade.

Pode-se supor que essa forma de conceber o processo ensino-aprendizagem, além de ser construída num contexto histórico-social mais amplo, é muitas vezes reforçada por discursos e pelas práticas de uma escola que não rompeu com o ensino seriado e com as práticas de reprovação.

O processo de ensino e aprendizagem é permeado por objetivos que devem ser alcançados em períodos predeterminados, podendo ser mais ou menos flexíveis dependendo da forma pela qual o ensino é organizado. A possibilidade de os alunos alcançarem esses objetivos está diretamente vinculada às condições de ensino oferecidas pela escola e às condições sociais e materiais dos alunos para a realização da aprendizagem, e não ao fato de o aluno ser reprovado.

No entanto, a reprovação é muitas vezes concebida como a medida pela qual a escola conduz os alunos a realizarem tais objetivos. Porém, ao ser uma medida a posteriori e não se tratar de um procedimento didático de ensino, ela não tem poder de garantir que o aluno aprenda, a não ser pelo fato de ele poder rever durante mais um ano letivo o conteúdo não aprendido. Contudo, sem intervenções pedagógicas adequadas, repetir a série ou o ano letivo não é garantia de aprendizagem: são as intervenções realizadas pela escola, pela família e pela sociedade que contribuem para que crianças e adolescentes realizem aprendizagens dentro de prazos definidos a partir do conhecimento acumulado sobre desenvolvimento e aprendizagem, e não a simples repetição nos anos letivos com as mesmas condições de ensino.

Não obstante, o baixo desempenho escolar e a compreensão fragmentada dos elementos que explicam essa realidade têm sido a base objetiva e subjetiva da defesa da reprovação por pais e alunos. 


\section{A reprovação como forma de pressionar o aluno a estudar}

A maioria dos pais e alunos de ambas as escolas expressou sua oposição à progressão continuada, argumentando que a reprovação é importante porque pressiona os alunos a estudar e, consequentemente, a uma melhor aprendizagem.

A reprovação precisa existir porque os alunos "não querem estudar", assim, havendo reprovação todos os anos, os professores podem obrigar os alunos a estudar.

Na opinião da maioria, a progressão continuada leva o aluno a estudar menos "porque ele não tem motivação, sabe que vai passar de ano, sabe que no próximo ano também não vai repetir; aí chega na 8토 série e não sabe nada e é obrigado a estudar demais ou é reprovado". Um dos alunos entrevistados explicou que isso ocorre porque os alunos "não vêm à escola somente porque eles querem, eles vêm por um tipo de obrigação, porque os pais querem, eles não estão a fim de estudar, estão lá porque se não estiverem os pais deles estariam obrigando a fazer isso".

Mães e pais entrevistados também compartilharam a opinião de que os alunos estudam menos porque não existe reprovação anual. Disseram que a progressão continuada é ruim "porque hoje em dia as crianças são espertas e elas já sabem que elas só são reprovadas por falta, então elas próprias não se esforçam, então isso eu não acho muito legal, eu acho que tinha que ser como antigamente".

A ideia de que a reprovação produz um sentimento de medo nos alunos também foi expressa pelos entrevistados. Ao ser questionados sobre se a reprovação anual deveria voltar, alguns responderam categoricamente: "Com certeza, porque se tivesse reprovação todo final de ano, eles ficariam com medo e estudariam desde o começo do ano, não só no final, com medo de ficar com bastante NS [não suficiente]".

A motivação e o interesse pelos estudos foram argumentos bastante usados pelas mães para justificar a reprovação anual:

Eu não sei explicar porque eu não estudei muito bem, mas eu acharia que tinha que ter reprovação porque o aluno fica mais motivado e se esforça mais;

Acho ruim porque as crianças não estudam, eles vão levando porque sabem que não vão reprovar; 
Eu já não concordo, no meu ponto de vista já deveria reprovar desde o começo, pra criança ter um interesse em estudar. Elas falam: "não vou estudar, vou passar".

A ideia da reprovação como instrumento para pressionar, motivar ou obrigar os alunos a estudar está presente na representação social que os entrevistados têm do processo educativo. Ao apresentar a reprovação como forma de motivar ou obrigar os alunos a estudar, eles parecem admitir a necessidade de medidas coercitivas para garantir o envolvimento dos jovens no processo educacional.

Embora essa tenha sido a perspectiva predominante entre os entrevistados, outras opiniões mostraram algumas contradições acerca da motivação para os estudos.

Questionada sobre se o medo da reprovação seria suficiente para os alunos desenvolverem hábitos de estudo, uma mãe disse concordar que, em se tratando de aprendizagem, é necessário que a pessoa tenha motivação interna para se mover em direção ao conhecimento e se apropriar dele, ou seja, ninguém pode aprender pelo outro. No entanto, em sua opinião, embora a reprovação possa não ser uma motivação externa totalmente eficaz, é pior não ter nada que pressione o aluno a estudar.

Totalmente não, mas eu acho que ainda é alguma coisa, é pior ficar sem nada, porque você não tem nem a vergonha de ficar repetindo, não é... Tudo bem, a minha sogra foi professora a vida inteira na rede pública e ela falou pra mim: "Olha! Eu não acredito muito nesse negócio de reprovação porque se um aluno reprova um ano tudo bem, mas no segundo ano a coisa já perdeu, não adianta mais". Então, tudo bem, eu considero que tenho que respeitar as demais experiências, mas, por outro lado, eu acho assim, pelo menos é uma tentativa, tem outros que repetem uma vez e não repetem mais...

Respaldada numa história de mais de um século, cujo processo de escolarização apoiou-se principalmente na pressão externa para conseguir determinados resultados escolares, essa mãe, assim como outras, teme que, ao retirar essas formas coercitivas de lidar com os alunos, a escola e os pais fiquem sem parâmetro para educar as crianças e os adolescentes. 
Ainda acerca da função da reprovação escolar como forma de pressionar o aluno a estudar, foi interessante perceber as contradições que surgiram nas falas dos sujeitos ao serem solicitados a dar exemplos práticos sobre como a reprovação tem contribuído para motivar os alunos a estudar.

Um aluno que havia estudado a 7ạ série numa escola privada disse discordar da progressão continuada nas escolas municipais porque se não tiver reprovação todo ano o aluno pode fazer o que quiser, ou seja, não estudar e mesmo assim ser promovido. No entanto, sua fala mostra elementos contraditórios a essa afirmação.

Aluno: Ah, eu acho melhor ter reprovação todo ano. Porque senão eu posso fazer o que eu quiser, ficar bagunçando na sala e, mesmo assim, passar de ano. Pesquisadora: Os alunos não estudam porque sabem que não reprova? Aluno: A maioria pode não estar nem aí porque sabem que não reprova, mas tem aqueles que se esforçam.

Pesquisadora: Se você comparar a sua experiência na 7ạ série na outra escola e agora nessa escola, você acha que os alunos estudavam mais lá ou estudam mais aqui? Aluno: Mais aqui.

Pesquisadora: Mas aqui não tem reprovação todo ano e lá tem! Será que a reprovação faz o aluno estudar? Será que o aluno estudará mais se souber que poderá ser reprovado no final do ano?

Aluno: Não, porque tem aluno que não está nem aí. Por exemplo, na escola particular, faz gastar dinheiro e ele não quer saber de estudar, nem de nada; aqui você não paga nada, mas parece que quer aprender porque tem menos condição de pagar uma escola...

Ao repetir uma ideia muito presente no meio educacional, o aluno não se dá conta das contradições entre fala e experiência. Ao não refletir sobre essas contradições, ele não consegue mudar a concepção. Assim, continua dizendo que a reprovação pressiona os alunos a estudarem, mesmo quando já verificou pela própria experiência que não é exatamente assim.

Outra mãe entrevistada também, apesar de ter afirmado que, se houvesse reprovação anual os alunos ficariam com medo e estudariam mais, 
não conseguiu exemplificar o que disse a partir da experiência com seu filho. Quando solicitada a analisar a atitude do filho no decorrer da escolarização, verificou que, apesar da não reprovação anual, até a "7ạ série" o filho estudava e tinha bom desempenho.

Pesquisadora: E por que você acha que teria de reprovar todo final de ano, em que isso contribuiria para a criança?

Mãe: Num ensino bem melhor, porque hoje os alunos vão da la a a 8a série, só na 8ª reprova o aluno devido nota e falta e aí termina o 3o colegial, não sabe nada.

Pesquisadora: E se eles fossem reprovados, você acha que eles aprenderiam mais?

Mãe: Com certeza, porque aí eles pensavam que se não estudarem vão ser reprovados, então o aluno vai brincando, vai brincando porque sabe que não vai reprovar.

Pesquisadora: Isso acontece com o Roberto? Ele estuda menos porque sabe que não vai ser reprovado?

Mãe: Desde os primeiros anos, não, mas na 7a e na 8 a ele deu essa cartada muito grande, não sei se é a idade, também. Agora ele está supermal, e eu acho que isso contribui também.

Observe-se como em dado momento da entrevista, ao lembrar que mesmo sem reprovação anual o filho sempre se havia dedicado aos estudos e tido bom desempenho, ela começou a pensar em outras hipóteses para explicar o comportamento do filho nos dois últimos anos, entre elas, as mudanças características da adolescência.

A ideia de que a ameaça da reprovação incide diretamente na disposição de estudar dos alunos parece não encontrar ressonância na atual realidade educacional. Talvez no passado esse discurso tenha sido verdadeiro, ao menos para uma parcela dos estudantes, aqueles que conseguiam galgar os níveis mais avançados de estudo. A escola tida como privilégio, ao excluir os que não respondiam a esse tipo de pressão, disciplinava seus alunos com base na coerção. No entanto, isso tem demonstrado não funcionar em uma escola para todos, porque ela precisa trabalhar também com aqueles que não se submetem a esse tipo de medida disciplinar. 
O depoimento a seguir mostra, em certo aspecto, que a experiência de uma aluna a levou a se rever quando pôde constatar que a ameaça da reprovação no final do 4 ano do ciclo II não reverteu a indisposição para estudar de alguns alunos, e que a inexistência de reprovação no final dos anos anteriores não fez a maioria dos alunos deixar de estudar.

O ano passado eu achava que era assim [referindo-se ao fato de os alunos não estudarem porque não há reprovação todo ano]: da 5ạ pra 6ạ série ou 7ạ as pessoas só reprovavam por falta, então não importava a nota. Tinha uma garota na sala que tirou todas as notas péssimas e ela passou de ano, não teve problema nenhum, então, por que ela ia estudar? Os pais também não se importavam muito. Já esse ano, lá na classe, a gente sabe que é perigoso, mas mesmo assim tem muita gente que não está nem aí.

Essa aluna deu ainda um exemplo por ela presenciado no ano da pesquisa, que mostra que a ameaça da reprovação causa um efeito contrário àquele que a maioria dos sujeitos disse ocorrer quando há reprovação anual: "Esse ano, um professor meu falou para uma aluna que ela estava praticamente retida. Dois dias depois ela tinha que fazer prova e disse que não ia fazer, pois disse que já estava praticamente retida e não ia adiantar nada". $\bigcirc$ anúncio de uma provável reprovação provocou um comportamento de desistência em relação aos estudos, não uma atitude de estudar mais.

Embora a maioria das falas expresse uma crença na reprovação como fator de motivação e de pressão para os alunos estudarem, algumas mães questionaram a validade de um estudo que se resume apenas a ter boas notas para ser promovido. Ao ser indagadas sobre a necessidade da reprovação escolar no processo educativo, responderam:

Eu acho que não precisa. É o tal negócio, a criança tem que manter o interesse, mas não pelo fato que não vai ser reprovada. Tem que mostrar mesmo que está querendo aprender. Então eu acho que necessariamente não precisa ter reprovação.

A reprovação eu acho que eles tinham o medo, porque vai chegar o fim do bimestre e "eu não vou estar com a matéria, se eu não alcançar a média eu 
vou ficar reprovado, entendeu?" Então, não sei se eles faziam para estimular o aprendizado ou se era só para ter as notas, porque ter a nota e não ter aprendido nada também não resolve muito. Quantos pais não falavam: se você não passar de ano, você não vai ter isso. Eu acho um erro fazer isso para estimular o filho a ir ao colégio: se você passar, você vai ganhar uma bicicleta, é mais ou menos por aí, ou passa de ano para ser premiado, não sei, fica meio difícil botar a culpa só na criança ou só na escola, são os dois em si.

Essas falas trazem uma questão importante acerca da utilização da reprovação para incentivar ou pressionar o aluno a estudar. Mesmo se a reprovação fosse um motivador para os alunos se dedicarem mais aos estudos, um processo educacional que se propõe a contribuir para a construção de sujeitos autônomos não se poderia pautar pela utilização desse recurso, sob pena de produzir um ensino voltado à preparação dos alunos para fazer provas e exames. A motivação para estudar deve estar no desejo de saber, na curiosidade de descobrir, de se aventurar por caminhos desconhecidos e de aprender coisas novas, e é nisso que a escola para todos precisa se pautar para ajudar os alunos a construírem os motivos para estudar.

Como explicou Leontiev (2004), pode-se começar a estudar porque é obrigatório e porque existem regras para serem cumpridas na escola, até mesmo porque é preciso tirar nota na prova, mas é fundamental que a escola contribua para que o principal motivo pelo qual o aluno estuda seja o desejo de aprender e não a necessidade de tirar boas notas. Isso, evidentemente, se se concordar que a escola não deve pautar sua prática educativa em métodos coercitivos e se entender a educação como um espaço essencialmente de persuasão ${ }^{8}$.

fato de a escola usar a promoção como o principal motivador do estudo produziu o chamado estudo para livrar-se de estudar. "É o problema da motivação extrínseca: a preocupação do aluno não é empenhar-se no estudo porque esteja ali, no estudo, intrinsecamente, o seu objetivo" (Paro, 200 I, p. I I I) Geralmente, ele estuda, muito contrariado, para se ver livre da pressão exercida pela família e pela escola.

Se quisermos que as crianças e os jovens construam hábitos de estudo associados ao desejo, à vontade e ao prazer de aprender e compreendam o

8. Usa-se o termo persuasão no sentido gramsciano, de convencimento por meio do diálogo. 
conhecimento como constitutivo do ser humano, não podemos ensiná-los por meio da coação e do respeito unilateral.

A regra da coação, ligada ao respeito unilateral, é considerada como sagrada e produz no espírito da criança sentimentos análogos àqueles que caracterizam o conformismo obrigatório das sociedades inferiores. Mas permanece exterior à consciência da criança e não conduz, como o desejaria o adulto, a uma obediência efetiva. A regra devida ao acordo mútuo e à cooperação enraíza-se, pelo contrário, no interior mesmo da consciência da criança e conduz a uma prática efetiva, na medida em que se associa com a vontade autônoma. (Piaget, 1994, p.270)

Nessa perspectiva, a ênfase da escola e, em certa medida, da família na motivação extrínseca leva a práticas de estudo desvinculadas da vontade autônoma da criança, dificultando que ela tome consciência de sua importância e necessidade. Assim, a maioria dos alunos aprende a estudar o estritamente necessário para tirar nota e se livrar da reprovação, sendo menos importante o que realmente fica de aprendizagem no final de cada ano letivo.

Embora preponderante nas falas dos entrevistados, a reprovação tida como instrumento para pressionar os alunos a estudar parece não estar cumprindo essa função na escola para todos. A contradição gerada entre uma crença e a sua não correspondência na realidade vivenciada pelos pais e alunos abre espaço para a percepção da necessidade de construção de outros meios para motivar e incentivar os alunos a estudar e para a construção de outra concepção de progressão continuada e de reprovação escolar.

\section{POR QUE PAIS E ALUNOS DEFENDEM A REPROVAÇÃO ESCOLAR? INTERPRETAÇÕES POSSÍVEIS}

Para compreender por que a maioria dos pais e alunos defende a reprovação escolar, serão discutidos os significados do conteúdo manifesto nas entrevistas, buscando compreender sua produção histórica a partir de dois grandes temas: as políticas de não reprovação anual no contexto do direito à educação e a defesa da reprovação escolar. 


\section{O direito à educação e as políticas de não reprovação}

Neste tópico se buscará compreender a posição hegemônica em torno da defesa das práticas de reprovação escolar partindo da dinâmica da construção da educação básica no Brasil. Para tanto são destacadas duas ideias das falas dos entrevistados: a reprovação como "consequência do baixo desempenho" e "como punição pelo pouco esforço".

Entende-se que as manifestações dos entrevistados relativas à defesa da reprovação escolar como punição pelo pouco esforço do aluno e pela necessidade de promover somente aqueles que alcançaram determinados objetivos, dado o baixo desempenho nas atividades escolares, são parte de uma compreensão acerca da apropriação individual e coletiva dos direitos sociais, historicamente construída e predominante na sociedade.

A ideia da educação como direito é bastante recente nos meios populares e as práticas escolares, de modo geral, ainda não respondem aos pressupostos desse direito.

Durante a pesquisa de campo, uma parte dos entrevistados fez referência às próprias experiências escolares para explicar a necessidade da reprovação escolar. Ao considerar as experiências escolares dos entrevistados como um condicionante da formação das opiniões expressas durante as entrevistas, pretende-se analisar como tais experiências foram interpretadas pelos pais e como elas têm sido interpretadas pelos alunos. Parte-se do pressuposto de que a compreensão que os sujeitos têm e a apropriação que fazem de suas experiências são influenciadas pelas diferentes ideias presentes na sociedade, em especial aquelas dominantes em cada momento histórico.

Daí se infere que a construção das concepções acerca dos processos educacionais escolares manifestadas pelos sujeitos foi e é condicionada pela forma pela qual cada um deles interpreta as suas experiências, tendo como referência um conjunto de ideias a que eles têm mais acesso e lhes é mais influente.

Assim, manifestar uma concepção de educação cujas práticas de reprovação são entendidas como necessárias é condizente com uma realidade social que prioriza a ação e a competência individuais em detrimento do direito social da igualdade de oportunidades. Este, ao contrário, exige uma educação escolar universal que promova o desenvolvimento de todos. 
A escola brasileira foi construída com base no mérito pessoal, que exige do aluno a capacidade de superar qualquer dificuldade, tanto objetiva quanto subjetiva, para adquirir o beneplácito do acesso à sociedade como cidadão. Nas palavras de Mariano Fernández Enguita:

... a escola contribui para que os indivíduos interiorizem seu destino, sua posição e suas oportunidades sociais como se fossem sua responsabilidade pessoal. Assim, os que obtêm as melhores oportunidades atribuem-nas a seus méritos e os que não as obtêm consideram que é sua própria culpa. As determinações sociais são ocultadas por detrás de diagnósticos individualizados, legitimados e sacralizados pela autoridade escolar. (1989, p. 193)

Pode-se dizer que os entrevistados aprenderam a conceber a promoção ao final de cada ano letivo como um mérito do aluno, fruto do esforço e da demonstração de "aprendizagem". Por isso, é estranho para eles ver alunos que "não se esforçaram" e "não responderam de forma adequada" às avaliações serem promovidos, como tem acontecido nas escolas com progressão continuada.

Nesse contexto, a ideia do empenho e da capacidade individual apresentada pelo liberalismo, e atualmente reforçada pelo neoliberalismo, contribui para a manutenção das opiniões que responsabilizam alunos e familiares pelo baixo desempenho e a consequente reprovação. Assim, ao continuar selecionando os que melhor respondem às suas exigências, seja pela reprovação, seja por não garantir os meios para todos aprenderem, a escola legitima a exclusão escolar e social por meio do chamado "mérito".

Em consequência, a escola ensina que o êxito é basicamente o resultado do esforço e da capacidade individual. Isso pode explicar, em parte, por que a maioria dos entrevistados atribuiu ao mau comportamento e à falta de dedicação aos estudos as reprovações vivenciadas por eles próprios ou pelos colegas.

A reprovação escolar também foi apresentada pelos entrevistados como forma de punição pelo mau comportamento e pela falta de empenho nos estudos. A ideia e as práticas de punição estão diretamente vinculadas às relações de mando e submissão, presentes tanto entre senhor e escravo quanto entre patrão e empregado, sendo reproduzidas na sociedade de modo geral e na família. 
Evidentemente, a concepção acerca da legitimidade da punição passou por mediações, consequência das mudanças ocorridas na sociedade e nas escolas. Não se intenta apresentar as práticas atuais de punição social e escolar como iguais às do início de século passado, mas chamar a atenção para o fato de estar presente, entre os alunos e pais, a ideia da necessidade delas, mesmo que aplicadas de forma diferente.

A reprovação é vista como forma de pressão para obter determinados comportamentos dos alunos e como punição para aqueles que não cumprem o esperado pela escola em relação à aprendizagem. Essa compreensão foi expressa pelos entrevistados, ao reivindicarem a reprovação para pressionar os alunos a estudar.

Nessa perspectiva, a posição da maioria dos entrevistados sobre os processos de promoção e reprovação na escola pode ser compreendida, em parte, pelos elementos que constituem a construção da escola graduada. As condições materiais e simbólicas de produção da escola apresentam-se como condicionantes das concepções dos pais e dos alunos a respeito do processo de escolarização.

Assim, embora a reprovação seja uma medida política e pedagógica construída pela escola para responder a uma forma de organização do ensino e à seleção dos mais aptos, ela se torna tão naturalizada aos olhos dos atores educacionais e da população que passa a ser concebida como algo inerente ao processo de ensino e de aprendizagem escolar.

\section{Aspectos ideológicos do apego à reprovação}

No tópico anterior, tentou-se construir uma compreensão do conteúdo manifesto por pais e alunos em relação à reprovação escolar, considerando a influência de alguns aspectos concernentes à construção da escola graduada no Brasil. Neste item se buscará complementar essa compreensão, considerando algumas ideias e opiniões predominantes na sociedade brasileira que podem ter contribuído para o posicionamento dos entrevistados em relação ao tema.

Se, por um lado, as justificativas dos sujeitos podem ser compreendidas com base em aspectos históricos e atuais de suas experiências de escolarização, 
por outro, também se verificou, nos depoimentos, a existência de elementos que poderiam ter produzido outro posicionamento sobre a reprovação escolar:

- Por que pais que, em sua maioria, não completaram a escolarização obrigatória por dificuldades muitas vezes impostas pela própria escola tendem a defender os mesmos procedimentos para a escolarização dos filhos?

- Por que, ao vivenciarem situações de aprendizagem insuficiente - às vezes devidas a um ensino de má qualidade -, alunos e pais defendem processos que podem limitar suas possibilidades de prosseguir nos estudos?

- Por que, mesmo diante de exemplos da ineficiência da pressão da reprovação para levar os alunos a estudar, a maioria dos entrevistados a continuou defendendo como instrumento necessário ao processo educativo escolar?

- Por que a reprovação continua sendo defendida como forma de o aluno aprender mais, quando pais e alunos já verificaram, pela própria experiência, a não veracidade dessa afirmação?

- Por que há pais e alunos que, teoricamente, diante de um mesmo contexto de escolarização defendem claramente a não reprovação anual?

Durante os depoimentos foram observadas, especialmente a partir dos questionamentos apresentados pela pesquisadora, contradições entre determinadas afirmações e o relato de experiências vivenciadas pelos entrevistados. Isso suscitou a questão: por que entrevistados, apesar de vivenciarem experiências que não confirmavam suas crenças, as afirmaram no momento da entrevista? Essa questão parece estar relacionada ao fato de as ideias dominantes na sociedade serem incorporadas às opiniões de pais e alunos, muitas vezes sem reflexão crítica. As opiniões não são confrontadas à realidade para que se saiba o quanto são pertinentes para explicar os fatos. Significa que a forma pela qual pais e alunos compreendem a realidade escolar está condicionada por um conjunto de ideias que, em certa medida, direcionam suas conclusões.

Quando se questiona por que as experiências dos pais com uma escola reprovadora e excludente não produziram, entre a maioria dos entrevistados, uma oposição a essas práticas, visto que houve aqueles que defenderam a 
progressão continuada, enseja-se acrescentar à discussão dois elementos: a presença das ideias dominantes na sociedade nas conclusões dos sujeitos a respeito de suas experiências; a especificidade da experiência de cada um em relação a tais ideias.

Assim, às experiências escolares vivenciadas pelos entrevistados parece ser necessário acrescentar a influência de determinadas ideologias para a sua compreensão e para a formulação das opiniões que foram emitidas. Junto com uma experiência de escolarização pautada na seleção, seja da ou na escola, os sujeitos convivem com ideias, produzidas especialmente pela classe dominante, que tentam explicar a realidade na perspectiva de manutenção das estruturas sociais e do status quo.

Foi necessário, para a classe dominante brasileira, sustentar uma escola elitista durante quase um século, construir uma ideologia que justificasse por que alguns podiam estudar enquanto outros, não. Nesse contexto, construiu-se, quase em forma de mito, a ideia de que nem todos tinham capacidade para estudar, sendo o estudo um privilégio dos "mais inteligentes", de modo geral, daqueles com maior poder econômico.

Embora a assimilação dessa ideia não tenha ocorrido de forma homogênea pelas classes populares, ela ainda está presente no pensamento de pais e alunos da escola pública. A repetição de algumas ideias incorporadas como verdades, independentemente de contradizerem suas experiências, mostra tanto a influência de algumas ideologias quanto a dificuldade dos entrevistados de questionar tais ideias a partir das próprias experiências.

Embora essa se apresente como tendência, há que ressaltar a existência de elementos que mostram contradições e heterogeneidade nas manifestações dos entrevistados, o que pode ser interpretado como a não incorporação, "ao pé da letra”, da ideologia predominante na sociedade, especialmente quando os sujeitos da pesquisa tiveram de refletir sobre suas experiências. Vale destacar, como exemplo, o depoimento da mãe que afirmou ser contrária à progressão continuada, usando as mesmas justificativas da maioria dos entrevistados; mas quando solicitada a falar sobre o caso do filho, concluiu que o baixo desempenho dele se devia à má qualidade do ensino e não aos motivos que ela havia utilizado para defender a reprovação anual.

Para falar de um contexto geral, sem se ater a situações concretas, ela e outros entrevistados reproduziram a ideia de que o baixo desempenho escolar 
é culpa do aluno, da família e da ausência de reprovação anual; mas, quando tiveram de se referir a uma realidade específica, às experiências de seus filhos, essa ideia não foi usada, embora continuasse fazendo parte da forma de pensar desses sujeitos.

Por que os entrevistados que relataram experiências parecidas não se perguntam se a explicação atribuída ao baixo desempenho escolar dos próprios filhos não poderia ser estendida à escola de modo geral? Por que, quando se trata dos alunos genericamente, a culpa do baixo desempenho escolar é a falta de interesse pelos estudos e a progressão continuada, mas, no caso do filho, é a má qualidade do ensino?

Se considerarmos que a formação das ideias ocorre no entrelaçamento da atividade da consciência com a atividade material, pode-se supor que as experiências dos pais e alunos em relação às próprias vidas fornecem elementos diferentes daqueles advindos das ideias dominantes; assim, quando falam de suas experiências, "abandonam", pelo menos momentaneamente, um discurso pronto e tentam apresentar ideias que lhes parecem mais plausíveis para explicar a realidade.

Entretanto, a mudança de determinadas concepções enraizadas na forma de pensar demanda espaços e possibilidades de reflexão. Não basta que as pessoas vivenciem experiências que lhes mostrem o contrário ou que questionem o que elas dizem: é necessária a introdução de novos conhecimentos, de outras formas de compreender e analisar um mesmo fenômeno para os sujeitos questionarem suas ideias e abrirem espaços para a construção de outras formas de pensar. Isso explica, em parte, por que, apesar das contradições entre vivências e discursos, os entrevistados tendem a reproduzir o discurso dominante ou apresentar explicações diferentes para um mesmo fenômeno.

Sobre a necessidade dos processos seletivos como instrumentos necessários à qualidade da educação escolar, expressa pela maioria dos entrevistados, pode-se perguntar em que medida essa concepção está respaldada nas ideias dominantes que explicam os processos de seleção e exclusão social.

Nas sociedades divididas em classes, a exclusão social é justificada por uma ideologia que atribui às características individuais, culturais e raciais - a situação de marginalização em que vive uma parcela da população. Assim, a miséria e a pobreza não são consequências, de acordo com a ideologia do- 
minante, do tipo de divisão social dos bens materiais e culturais inerentes às sociedades capitalistas, mas da ação inadequada das pessoas ou dos grupos.

Essa forma de pensar leva, muitas vezes, as pessoas a atribuírem a condição de pobreza à sua incapacidade individual de responder adequadamente às exigências da sociedade. $\mathrm{Na}$ escola, isso se reproduz quando se reivindicam os processos seletivos como legitimadores da aprendizagem dos promovidos e da não aprendizagem dos reprovados. Assim, ao não oferecer oportunidades de aprendizagem a todos, a escola reproduz diferenças sociais como se fossem individuais e a avaliação escolar é o principal procedimento para legitimar a seleção por meio da promoção e da reprovação:

$\mathrm{Na}$ escola aprende-se a estar constantemente preparado para ser medido, classificado e rotulado; a aceitar que todas nossas ações e omissões sejam suscetíveis de ser incorporadas a nosso registro pessoal; a aceitar ser objeto de avaliação e inclusive a desejá-la. (Fernández Enguita, 1989, p.203)

As opiniões dos pais e dos alunos sobre a progressão continuada e a reprovação escolar, colhidas nas entrevistas e confirmadas durante as visitas, sugerem a permanência de ideologias que sustentam uma concepção de educação como privilégio e um conjunto de concepções que compõem o ideário liberal. Isso se verifica especialmente no que diz respeito à individualização de problemas sociais: "a solidariedade e a cooperação cedem lugar assim à competição e ao mérito individual como metas educacionais finais" (Suárez, 1995, p.262). É o que explica, em parte, por que muitos pais e alunos foram tão categóricos ao atribuir ao aluno e à família a responsabilidade primeira pelo desempenho escolar, mesmo reconhecendo as influências do contexto mais amplo como condicionantes do comportamento e das atitudes dos alunos em relação aos estudos.

Embora estruturante do discurso, essa ideia tem sido, contudo, permeada por elementos que correspondem à mudança de mentalidade acerca da educação e da aprendizagem. Pais e alunos convivem com concepções sobre o desenvolvimento e a aprendizagem humana que questionam a determinação de características inatas para a aprendizagem, por isso sabem, mesmo de forma fragmentada, que todos podem aprender se Ihes forem dadas condições para tanto. Permanecer na escola, apesar de sucessivos "fracassos", é um indicativo da expectativa de que poderão aprender, bem como da percepção de 
seu direito à educação combinado à obrigatoriedade do ensino fundamental. Essa sobreposição de ideias, muitas vezes contraditórias, produz um discurso fraturado sobre as políticas de não reprovação.

\section{CONSIDERAÇÕES FINAIS}

Os dados obtidos na pesquisa confirmam o que dizem outros trabalhos sobre a questão e contribuem para a elucidação dos motivos apresentados pelos pais e pelos alunos para se oporem à progressão continuada.

As contradições das falas dos pais e dos alunos, que remetem à existência de fraturas no discurso de oposição à progressão continuada, ocorrem porque as experiências que eles tiveram não necessariamente corroboram os motivos apresentados para justificar a defesa da reprovação anual. Em certo sentido, isso facilita a introdução de conhecimentos e concepções que questionam as opiniões majoritárias dos sujeitos, na medida em que encontra ressonância também nas suas experiências.

Do ponto de vista das políticas educacionais, esse dado sugere a importância de se considerar tanto a oposição e a resistência dos pais e dos alunos às políticas de não reprovação quanto a necessidade de introduzir conhecimentos que contribuam para questionar as ideias que as justificam.

O convencimento dos pais e alunos sobre a pertinência das políticas de não reprovação requer a vivência de experiências escolares de progressão continuada favoráveis a uma educação de boa qualidade. É preciso que o ensino organizado em ciclos e as condições de funcionamento das escolas ofereçam aos pais e aos alunos uma experiência educacional que os leve a questionar a crença na necessidade da reprovação. Enquanto educadores, pais e alunos estiverem presos a uma concepção que atribui à reprovação a possibilidade de melhor aprendizagem ou melhor qualidade do ensino, haverá questionamentos e oposições às políticas de não reprovação.

Contudo, a não unanimidade em torno da reprovação, as contradições entre algumas opiniões e as experiências dos pais e alunos, bem como a disponibilidade manifesta por alguns de refletir sobre suas opiniões mediante a introdução de outras informações sobre o tema, demonstram que há espaço para se potencializar discussões acerca da efetivação do direito à educação, para além da polêmica "progressão continuada versus reprovação". Se a escola 
é eficiente na forma de ensinar e os alunos contam com as condições materiais para realizar sua escolarização, os processos de promoção da aprendizagem e de formação dos alunos tenderão a substituir os processos avaliativos que respaldam a reprovação escolar.

\section{REFERÊNCIAS BIBLIOGRÁFICAS}

ABREU, R. C. Famílias de camadas populares e o Programa Escola Plural: as lógicas de uma relação. 2002. Dissertação (Mestrado em Educação) - Faculdade de Educação, Universidade Federal de Minas Gerais, Belo Horizonte.

ALMEIDA JÚNIOR, A. F. E a escola primária? São Paulo: Nacional, 1959.

AMBROSETTI, N. B. Ciclo básico: uma proposta vista pelos professores. Cadernos de Pesquisa, São Paulo, n.75, p.57-70, nov. 1990.

ARAÚJO, M. I. B. Resistência docente à escola ciclada. Brasília: Liber Livro, 2006.

BARDIN, L. Análise de conteúdo. 3. ed. Lisboa: Edições 70, 2004.

BRASIL. Lei n. 4.024, de 20 de dezembro de 1961. Estabelece as diretrizes e bases da educação nacional. Diário Oficial [da] República Federativa do Brasil, Brasília, 27 dez. 1961.

. Lei n.5.692, de II de agosto de 197I. Fixa diretrizes e bases para o ensino de Io e 2o graus. Diário Oficial [da] República Federativa do Brasil, Brasília, 12 ago. 1971.

. Lei n. 9.394, de 20 de dezembro de 1996. Estabelece as diretrizes e bases da educação nacional. Diário Oficial [da] República Federativa do Brasil, Braślia, 23 dez. 1996.

- Ministério da Educação. Instituto Nacional de Estudos e Pesquisas Educacionais Anísio Teixeira. Matrícula por forma de organização e dependência administrativa, Brasil e São Paulo (Estado e Município): 2005. Brasília, 2005.

. Ministério da Educação. Secretaria de Educação Fundamental. Parâmetros curriculares nacionais. Brasilia, 1997.

FERNÁNDEZ ENGUITA, M. A Face oculta da escola: educação e trabalho no capitalismo. Porto Alegre: Artes Médicas, 1989.

GLÓRIA, D. M. A. A "Escola dos que passam sem saber": a prática da não retenção escolar na narrativa de alunos e familiares. Revista Brasileira de Educação, Rio de Janeiro, n.22, p.61-76, 2003. 
GRAMSCI, A. Maquiavel, a política e o Estado moderno. Rio de Janeiro: Civilização Brasileira, 1968.

JACOMINI, M. A. Reprovação escolar na opinião de pais e alunos: um estudo sobre os ciclos e a progressão continuada na Rede Municipal de Ensino de São Paulo. 2008. Tese (Doutorado em Educação) - Faculdade de Educação, Universidade de São Paulo, São Paulo.

- Uma década de organização do ensino em ciclos na rede municipal de São Paulo: um olhar dos educadores. 2002. Dissertação (Mestrado em Educação) - Faculdade de Educação, Universidade de São Paulo, São Paulo.

LEONTIEV, A. O Desenvolvimento do psiquismo. 2. ed. São Paulo: Centauro, 2004.

MAGALHÃES, C. R. Escola e famílias: mundos que se falam? Um estudo no contexto da implementação da progressão continuada. 2004. Tese (Doutorado em Educação) - Centro de Educação e Ciências Humanas, Universidade Federal de São Carlos, São Carlos.

PARO, V. H. Reprovação escolar: renúncia à educação. São Paulo: Xamã, 200 I .

PIAGET, J. O Juízo moral na criança. 3. ed. São Paulo: Summus, 1994.

RIBEIRO, E. Alunos da rede estadual chegam à 5a série sem saber escrever: pais dizem preferir reprovação. Agora São Paulo, São Paulo, p.A-4, 4 maio 2000.

STEINVASCHER, A. A Implantação da progressão continuada no Estado de São Paulo: um caminho para a democratização do ensino? 2003. Dissertação (Mestrado em Educação) Faculdade de Educação, Universidade de São Paulo, São Paulo.

SUÁREZ, D. O Princípio educativo da nova direita: neoliberalismo, ética e escola pública. In: GENTILI, P. (Org.). Pedagogia da exclusão: crítica ao neoliberalismo em educação. Rio de Janeiro: Vozes, 1995. p.253-270.

VIÉGAS, L. S. Progressão continuada e suas repercussões na escola pública paulista: concepções de educadores. 2002. Dissertação (Mestrado em Psicologia) - Instituto de Psicologia, Universidade de São Paulo, São Paulo.

WEBER, D. Sistema de ciclos esconde baixa qualidade. O Estado de S. Paulo, São Paulo, p. A-8, 28 set. 2000. Disponível em: <http://www.gecities.co/ResearchTrangle/Lab/6 | |6/ aprovacaoautomatica.html>. Acesso em: 20 jan. 2008.

Recebido em: agosto 2008

Aprovado para publicação em: novembro 2008 